\title{
Da Fórmula Porchat: conflito das filosofias, vontade de incredulidade, decidibilidade
}

\author{
Renato Lessa \\ PUC-Rio / Universidade de Lisboa / CNPq
}

\section{RESUMO}

A Fórmula Porchat - ou seja, a intuição de um conflito das filosofias de caráter indecidível - possui papel tanto propedêutico quanto compulsório para um tratamento não dogmático da história dos sistemas filosóficos. Ao mesmo tempo em que reconhece tal papel, o presente artigo pretende indicar o caráter problemático da correspondência entre "conflito das filosofias" e "indecidibilidade filosófica”. Para tal, sustenta que o sentimento de indecidibilidade filosófica tem como referência impensada uma nostalgia da decidibilidade. $\mathrm{O}$ artigo sugere, ainda, $\mathrm{o}$ abandono do tema da indecidibilidade, como um falso problema filosófico, e sustenta a necessidade de considerar os efeitos da prática filosófica sobre a configuração da vida comum e de tomar tais efeitos como formas de decidibilidade. Para tal é necessário considerar a atividade filosófica como inscrita no campo maior da manufatura da experiência humana.

\begin{abstract}
The Porchat Formula - i.e., the intuition of an undecidable conflict of philosophies - has both propaedeutic and compulsory role for a non-dogmatic treatment of the history of philosophical systems. While acknowledging such a role, the present article intends to point out to the problematic character of the supposed correspondence between "conflict of philosophies" and "philosophical undecidability". To this end, it maintains that the feeling of philosophical undecidability has as its unthinking reference a kind of nostalgia for decidability. The article suggests abandoning the topic of undecidability as a false philosophical problem and sustains the need to consider the effects of philosophical practice on the configuration of ordinary life and to take such effects as forms of decidability. For this it is necessary to consider philosophical activity as inscribed in the larger field of the manufacture of human experience.
\end{abstract}


...uma simplicidade que é, talvez, o fruto de uma requintada sofisticação.

Oswaldo Porchat Pereira, "Prefácio a uma Filosofia"

Qual o arquétipo, Urbild, da insatisfação? O espaço vazio?

L. Wittgenstein, Investigaçöes Filosóficas, 439

1.

O tema do conflito das filosofias pode ser considerado o problema originário da filosofia de Oswaldo Porchat Pereira. Não no sentido literal da cronologia da trajetória, mas no tempo filosófico da gestação de uma perspectiva própria, que viria a desaguar no programa de reconstrução filosófica do neopirronismo. Por certo, Porchat já possuía sólida trajetória na altura em que proferiu, aos 35 anos de idade, a Aula Inaugural de I968, no Departamento de Filosofia da USP, na qual discorreu sobre o tema ${ }^{1}$. Pareceme, contudo, inegável que a fórmula "conflito das filosofias", uma vez posta, ao mesmo tempo em que organizava retrospectivamente o trajeto de seu autor, indicava abertura de campo reflexivo novo, marcado por forte diferendo com relação às tradiçôes e linguagens filosóficas dogmáticas e aos programas a elas associados.

A forma da aula não deixa margem à dúvida: há ali algo de confessional; algo que implica o sujeito naquilo que diz e que o pressupóe como elemento ativo. Ainda que a primeira pessoa do singular não apareça, tal como o fará em textos porchatianos posteriores e notáveis, ${ }^{2}$ o leitor é levado a considerar as questóes postas como além de dotadas de relevância, digamos, "objetiva" — reveladoras de marcas de um envolvimento pessoal denso com o que se ali diz. Em grande medida, trata-se de um relato a respeito do processo de configuração de uma persona filosófica precisa - a do philósophos que não se faz filósofo —, movida pela recusa a dogmatizar. Impossível não perceber o quanto o autor estava implicado no relato. Talvez tenha sido uma das principais liçóes deixadas por Oswaldo Porchat Pereira em suas obras e intervençôes, a de que o trabalho no campo da Filosofia dá-se mal com uma cultura intelectual que trata seus objetos, para dizê-lo à moda durkheimiana, como "coisas" que "acontecem" no exterior do sujeito que investiga.

\footnotetext{
1 Aula inaugural do Departamento de Filosofia da Universidade de São Paulo, proferida em março de I968 e publicada na Revista Brasileira de Filosofia, vol. XIX, fasc. 73, São Paulo, janeiro-março, 1969, p. 3-I5. Publicada também em Prado Jr, Porchat Pereira e Sampaio Ferraz, 1981; em Porchat Pereira, 1993, p. 5-21 e em Porchat Pereira, 2006, p. 13-23.

2 Tal como "Prefácio a uma filosofia", do qual retirei a epígrafe deste texto, e tantos outros que se lhe seguiram. Ver, para a primeira publicaçáo do texto, Porchat Pereira, 1975, p. I05-I32. O texto viria ainda a ser publicado nos três livros de Porchat — o primeiro deles coletivo — citados na nota anterior.
} 
A sképsis porchatiana, ao contrário, mostrou durante todo o tempo de sua vigência o quanto o envolvimento genuíno e empenhado com questóes de natureza filosófica constitui um modo da filosofia, algo que se dá necessariamente no seu interior. Parece-me ser este um dos sentidos possíveis do mote de Blaise Pascal, aqui devidamente flexionado, - vous (nous) êtes (sommes) embarqués - e, bem antes dele, da passagem de Aristóteles, no Protréptico, citada pelo próprio Porchat: "Se se deve filosofar, deve-se filosofar e, se não se deve filosofar, deve-se filosofar; de todos os

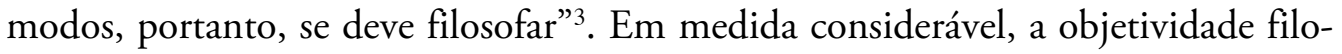
sófica, por assim dizer - i. e., tratar da natureza e dos significados dos sistemas filosóficos - exige visibilidade a respeito dos circuitos internos que afetam o espírito dos que se devotam a tal faina, sem que isso implique operar no modo umbilical do confessionalismo.

\section{2.}

Interessa-me, nestas notas, refletir a respeito do mote do "conflito das filosofias", na condiçáo de um sujeito afetado pelo impacto que o texto inaugural de Porchat teve sobre o próprio trabalho que desenvolve no campo da filosofia política. Devo acrescentar: segue e seguirá a ter. Em tal medida, náo tratarei dos desdobramentos da reflexão de Porchat, na direção da perspectiva que veio a construir. Menos do que indagar sobre a natureza "real" de seu neopirronismo ulterior, e de eventuais impasses ou virtudes ali contidos, gostaria antes de "congelar" o que aqui apresentarei nos termos de uma Fórmula Porchat, e subscrever seu papel tanto propedêutico quanto compulsório para um tratamento não dogmático da história dos sistemas filosóficos. Ao mesmo tempo, desejo indicar o caráter problemático da correspondência que sustenta entre "conflito das filosofias" e "indecidibilidade filosófica".

Adianto o foco: parece-me que o ponto de partida do argumento de Porchat —o "conflito das filosofias" - não implica de modo necessário o ponto de chegada, a "indecidibilidade, sendo esta tão somente um de seus resultados possíveis. Para sustentar a hipótese da não implicação automática, julgo ser necessário rediscutir os termos que estabelecem o quê deve constituir o campo de prova ou, em outros termos, o lugar da decidibilidade. Em outros termos, trata-se de pôr em juízo os termos tidos por necessários para dizer que alguma questáo possa ser tomada por "decidível”. Com efeito, o quê se deve exigir como condição positiva de decidibilidade? Em que medida

3 Cf. Fragmento 5I R3 (Elias in Prolegomena Philosophiae, 3, 17-23), Cf. Jonathan Barnes e Gavin Lawrence, I984, p. 2416. 
juízos de indecidibilidade carregam consigo, como fantasma, o modelo da decidibilidade? Na verdade, suspeito que a decidibilidade filosófica, mais ou menos que impossível, pode ser considerada simplesmente como algo que não faz sentido, e que talvez tal suspeita indique o experimento próprio de uma filosofia não-dogmática ${ }^{4}$.

Os âmbitos da ética, da filosofia moral e da filosofia política - domínios que têm parte indelével com as formas de vida — são obrigados, por maioria de razão, a lidar com o problema da decidibilidade de um modo próprio que, a meu juízo, não pode excluir como "campo de prova" os efeitos que enunciados filosóficos produzem o comportamento humano, em suas ações e configuraçóes. A questão toda consiste em saber se os experimentos de passagem ao ato, ${ }^{5}$ provenientes de concepçóes de mundo tecnicamente dogmáticas, devem ou não ser considerados como aspecto relevante para o reconhecimento da existência de operadores de decidibilidade a respeito de proposiçóes e imagens de mundo filosoficamente produzidas.

\section{3.}

Para melhor estabelecer a questáo, parto da proposição originária — a Fórmula Porchat - , cujo corolário é "a experimentação do caráter 'indecidível' do discurso filosófico" (Porchat, I98I, p. II):

... a história da filosofia brinda-nos com o desfilhe quase ininterrupto dos grandes sistemas que, uns com os outros sempre incompatíveis, se apresentam animados, todos e cada um, da mesma pretensão de representar a verdadeira solução dos problemas do ser e do conhecer, a ediçáo nova e definidora da realidade (Ibid.).

Porchat propôs-nos, com o enunciado, a descrição de uma cena primitiva composta por uma distribuição natural dos sistemas filosóficos. Ou, se quisermos, uma descrição naturalista a respeito do estado primário dos mesmos. Antes de qualquer juízo particular a respeito de cada um deles, tratar-se-ia do quadro natural de um estado de coisas preenchido por sistemas filosóficos discretos e discrepantes. Se o mundo é mesmo "tudo o que é o caso", o "caso" - em se tratando de filosofia é o "conflito das filosofias": é esta, filosoficamente, a condição primária, o bedrock.

4 O tema da "decidibilidade" faria tanto sentido para uma filosofia não-dogmática quanto, para teólogos agnósticos, os da existência e dos atributos de Deus.

5 Um experimento de passagem ao ato, no contexto no qual discuto, é, por exemplo, o Preambulo da Declaração de Independência norte-americana: "Tomamos tais verdades como auto evidentes, que todos os homens são criados iguais, dotados pelo Criador de certos direitos inalienáveis, que entre estes estão a vida, a liberdade e a procura da felicidade". Trata-se, com efeito, de enunciado impensável sem o socorro de operadores filosóficos precisos, elaborados a partir do século XVII: a ideia moderna de evidência — algo cuja verdade é index sui - e sua fusão com o vocabulário lockeano dos direitos naturais. 
Para dizê-lo à moda de John Ralws: é esta a sua posição originária. Adesões dogmáticas a cada um dos sistemas em conflito dáo-se a jusante desse estado de natureza filosófico, condição que as incapacita inapelavelmente para abrigar de modo genuíno qualquer intuição agnóstica a respeito de uma diversidade originária.

Impóe-se, assim e antes de tudo, pensá-los — os sistemas filosóficos — como distintos. As marcas de distinção são, por sua vez, auto declaratórias. Cada sistema diz de si mesmo, por meio de enunciados de auto validaçáo, já que movido pela "pretensão de representar a verdadeira solução dos problemas do ser e do conhecer, a edição nova e definidora da realidade” (Ibid., p. 3). E isto só se dá a ver por obra e graça de enunciados e gestos auto declaratórios. Sáo os movimentos das mãos de Platão e de Aristóteles, por exemplo, que o indicam de modo inequívoco, através da representação pictórica de Rafael Sanzio a respeito da discrepância das filosofias, em sua obra A Escola de Atenas (c. I5IO).

O dedo platônico apontado para os céus e a palma da máo aristotélica voltada para o chão podem ser tomados — e esse foi o efeito pretendido por Rafael — como sinais auto declaratórios que, com um movimento corporal, resumem o núcleo fundamental de cada um dos dois sistemas ali em conflito. A verdade, portanto, não advém de reconhecimento externo. Ela é, antes, uma propriedade inalienável dos sistemas que se querem verdadeiros, além de marcador epistêmico dos sujeitos que os sustentam. Supô-la advinda de um juízo exterior aos sistemas em conflito implica sustentar a possibilidade de uma observação inocente de eventuais adequaçóes e inadequaçóes entre discurso e mundo, como se este subsistisse na exterioridade e na ausência do primeiro.

O enunciado da Fórmula Porchat poderia ser considerado como legenda mais do que adequada à obra em questão de Rafael Sanzio. Esta, por sua vez, seria a forma pictórica da Fórmula Porchat. Trata-se, com efeito, da ostensão a cores da diaphonía. Formulada pelo cético Agripa, em um de seus Cinco Modos, a intuição da diaphonía teria aguardado quase dois mil anos para encontrar inequívoca expressão visual. A representação exibe parte da demografia filosófica da antiguidade grega, composta por filósofos dispostos alguns de modo isolado e individualizado, cada qual com sua alucinação específica, e outros a querelar. No proscênio, dá-se o destaque da "mãe de todas as querelas", a que opunha Platão - com ares de Leonardo da Vinci - a Aristóteles - segundo alguns modelado a partir da figura de Michelangelo. O primeiro aponta os céus - ou, o que é mais provável, as Formas —, com a ajuda axilar do Timeu; o segundo, com idêntico apoio de sua Ética, estende o braço com a palma da mão voltada para o chão, não se sabe se a indicar de modo mundano o chão ordinário, indigno do trabalho da especulação filosófica, ou o chão metafísico, condição de vigência para todos os chãos. 
De qualquer modo, a representação pictórica sugere um ânimo cético em seu autor, que ostenta, tal como historikós empenhado no trabalho pictórico, sua imagem da querela filosófica: mostrar a discrepância. Diferentemente de Apeles, seu antecessor de ofício, que obteve de modo casual o efeito da espuma na boca de um cavalo que acabara de pintar, Rafael não gerou seu efeito pictórico por meio das artes do acaso ${ }^{6}$. O cenário ali exposto da diaphonía náo resultou de uma desistência de pintar, seguida do arremesso irritado do pincel à representação. Seria risível supor que o registro rafaeliano do dissenso filosófico resultasse de uma técnica de arremesso de pincéis à tela, para gerar efeitos aleatórios e conclusivos, um recurso ainda não disponível aos artistas renascentistas.

Entre a espuma acidental do cavalo pintado por Apeles e a representação rafaeliana da demografia filosófica grega originária opera um abismo filosófico. Em outros termos, ali a visão da diversidade e da dissonância dos filósofos parece ter exigido adesão prévia a um modo próprio de conceber o espaço filosófico, a um só tempo pagão e equipolente. Por que não supor que o mesmo tenha se dado com o observador hodierno do "conflito das filosofias"?

\section{4.}

A dissonância dos gestos auto declaratórios constitui evidência primária de uma diversidade conflituosa: cada um ao falar de si faz-se critério para descrever os demais. Os atos auto declaratórios, na verdade, possuem dupla valência: a um só tempo afirmam e refutam. Constituem, assim, o quadro natural de inteligibilidade para tudo aquilo que os contendores falam a respeito de si mesmos e de seus rivais. Clara está, portanto, a impossibilidade epistemológica de acolhimento, por parte dos sistemas dogmáticos, de uma intuição semelhante à contida tanto na Fórmula Porchat como na Forma Sanzio: "pertence a cada filosofia o dever impor-se como a única e verdadeira Filosofia" (Porchat, 198I, p. I3). Não há, ademais, naqueles sistemas abrigo para a ideia de indecidibilidade. Porchat está, portanto, coberto de razão quando diz que "o conflito das filosofias não constitui, em verdade, um problema realmente sério para as filosofias dogmáticas, porque estas já o têm, por definição, resolvidos" (Ibid., p. I8).

Para todo e qualquer sistema dogmático, o elemento residual e comum à comunidade de insipientes que compóe o conjunto dos demais sistemas rivais, dada sua "mútua e recíproca excomunhão e exclusão" (Ibid., p. I3), está resumido na ideia de

6 Trata-se de conhecida passagem das Hypotyposes, nas quais Sexto Empírico sugere que a ataraxia chega ao cético, tal com o efeito estético da espuma da boca do cavalo de Apeles. Cf. Sexto Empírico, Outlines of Pyrrhonism, I, 28-29, 1986, p. 19-2I. 
erro filosófico. Um dos méritos indisputados da Fórmula Porchat é a dissolução dessa ideia, sendo a indecidibilidade o operador central de tal desfazimento. $\mathrm{O}$ efeito, por sua vez, exige a presença e a ação de um tipo peculiar de observador filosófico, dotado de uma dynamis própria, movida por uma vontade de incredulidade. Somente a tal observador se apresentará "o desfile quase ininterrupto dos grandes sistemas [...] uns com os outros sempre incompatíveis" (Ibid., p. II). A outros observadores, parece-me compulsório admitir, tal "desfile” poderá significar tão somente oportunidade e motivação maiores para seguir a dogmatizar.

Juízos de verdade a respeito de um sistema filosófico só podem ser adultamente pensados como atos de auto verificação. Um juízo externo de veracidade é, na verdade, uma quimera filosófica: qualquer enunciado de adesão a um determinado sistema filosófico será por definição um elemento interno ao sistema em questão; serão os termos deste último que indicarão o sentido e a linguagem da adesão. A Fórmula Porchat parece supor, em direção diversa, a presença de um observador singular a um só tempo "metafilosófico" e "neutro" —, habitante de uma exterioridade radical a todos os sistemas existentes. Contudo, a natureza do observador, nos termos postos pelo autor da fórmula, sabe à ambiguidade.

Por vezes, trata-se de alguém, "intimamente familiarizado com diferentes universos filosóficos" (Ibid., p. Io) - tal como a persona filosófica que narra o ensaio "Prefácio a uma filosofia", que se fartou de buscar respostas. Assolado pelo espetáculo da sucessão imparável de petiçóes de verdade reciprocamente incompatíveis, tal observador vê-se um tanto espantado em meio a um jogo circular sem possibilidade de saída, já que não há resposta que não seja passível de refutação. No limite, é-lhe insuportável estar no conflito, ser dele um de seus sujeitos e agentes.

Em outras passagens é a figura de um observador pré/não-filosófico que se apresenta, um "espectador que acompanha, do exterior e anteriormente a qualquer opção de natureza filosófica, as manifestaçôes do pensamento filosófico através do tempo" (Ibid., p. 13). Se no primeiro caso, um certo cansaço filosófico torna plausível a saturaçáo da vontade de dogmatizar, no segundo o quadro revela-se mais problemático. Com efeito, a esse espectador pré-filosófico — sujeito de uma inocência pré-lapsária - é exigida a posse de um conjunto robusto de sensores filosóficos. De seu posto de observação - isto é, através de seu olho - vislumbra-se: a longa sucessão histórica de sistemas filosóficos, "diferentes graus e matizes de interpretação", ausência de "unidade de método ou de temática" (Ibid.). O quadro completo da visão

7 É o que sustenta o argumento apresentado em resposta de Porchat ao comentário de Tércio Sampaio Ferraz ao texto de sua Aula. Cf. Sampaio Ferraz, "A filosofia como discurso aporético" e Porchat, "Breve reposta", I98I, p. 38 . 
que se apresenta ao espectador externo e pré-filosófico foi belamente desenhado por Porchat:

...a filosofia aparece-nos como uma multiplicidade historicamente dada de filosofias, identicamente empenhadas, todas elas, na elucidação da própria noção de filosofia e identicamente confiantes na própria capacidade de resolver essa questão de princípio e de executar de maneira adequada o programa que o mesmo empreendimento de auto definição implicitamente lhes trata (Ibid.).

\section{5.}

A questão é: como isto se dá a ver? A carga inscrita naquele aparecer sugere uma densidade nada ordinária e excessiva, se imaginarmos a figura de um observador pré-filosófico. O quê se requer para que uma visão desse tipo seja possível? Trata-se, de modo não mediado, de um acolhimento perceptual passivo de propriedades naturais ou, ao contrário, de algo que um espectador com olhos de Franz Boas - para quem "o olho que vê é órgão da tradição" - lá póe e fixa na linguagem como se fosse sua descrição natural? Em outros termos, é o "conflito das filosofias" — tal como posto na Fórmula Porchat - propriedade natural de uma distribuição primária de sistemas filosóficos?

Desde já, deixo claras as minhas intençôes: desnaturalizar não implica reduzir a potência da Fórmula Porchat. Trata-se, ao contrário, de sustentar a sua valência, mesmo supondo que se trata do enunciado de uma propriedade não-natural e, como tal, inscrita no campo dos enunciados filosóficos possíveis.

Tanto o cansaço do filósofo maduro quanto a inocência ocular do espectador externo são, a meu juízo, causas insuficientes da intuição do conflito das filosofias, segundo os termos da Fórmula Porchat. Entre a suposta causa e o seu efeito, cabe supor a intervenção de um operador silente, pero activo, cujas premissas são inerentes ao próprio ato de descrição. Falo de um operador de incredulidade que só é inteligível - e possível - se referido à uma cultura de dúvida e autocontenção predicativa, que não pode deixar de ter fundamento filosófico ${ }^{8}$. Tal operador não é outro senão o resultado da disposição - dynamis — dos pirrônicos originários tal como a descreveu Sexto Empírico, que seria a marca que distingue os céticos das demais modalidades de filosofia, sintetizadas em dois conjuntos: a dos dogmáticos e a dos acadêmicos (Sexto Empírico, 1986, vol. I, p. 3).

\footnotetext{
8 Tal como a que se insinua no comportamento do cético que evita a proposição assertiva "isto é $x$ ", e opta pela fórmula "isto parece ser $x$ ", tal como no comentário de Timon a respeito da doçura do mel. $C f$. Sexto Empírico, 1986, p. I5.
} 
Parece-me problemático supor, portanto, que tal disposição seja o resultado do encontro entre um observador inocente e um estado de mundo composto por enunciados discrepantes e naturalmente marcado por um princípio constitutivo de equipolência — ou pelo "conflito das filosofias". Não há equipolência que não seja precedida por sua inscrição prévia, como antecipação de uma forma do mundo, no olho que quem a vê. É o próprio Porchat ao sugeri-lo, quando enumera, no texto de sua Aula Inaugural, seus compagnons de route: Protágoras, Górgias, Agripa e Sexto Empírico, "os poucos pensadores que se opóem à extensa galeria dos metafísicos de todos os tempos” (Porchat, I98I, p. Io). Com efeito, o quê esperar do quarteto senão a imagem de um estado de coisas filosófico marcado pela variedade e pela discrepância?

Inclino-me pela implicação contrária: somente a olhos configurados por aquela dynamis, a visão da equipolência dos enunciados humanos — filosóficos ou não — se apresenta. Trata-se de uma das aplicaçóes possíveis de uma ideia posta por Wittgenstein: "A nossa expectativa antecipa o acontecimento. Neste sentido, ela faz um modelo de acontecimento" (Wittgenstein, 1998, p. 67). O cético, nesta mesma medida, prepara a sua epoché, dada a sua orientação filosófica prévia de tomar os fenômenos como seu critério e de investigar o que dizem os filósofos a respeito da real natureza de todas as coisas. O princípio da equipolência é, neste sentido, a enunciação de um problema filosófico e não o nome natural de uma discrepância. Como tal, ele é a condição mesma de possibilidade da recusa do valor de verdade das petiçóes dogmáticas. Ele é, neste sentido, o suporte da dúvida e do operador de incredulidade.

É a sombra do \$II4 de Sobre a Certeza, de Wittgenstein que parece se impor: "Se tentássemos duvidar de tudo, não chegaríamos a duvidar de nada. O próp jogo da dúvida pressupóe certeza" (Id., I969, \ II5). Na precisa aplicação da proposição, feita por Danilo Marcondes, é bem o caso de considerar que "a dúvida pressupóe um horizonte de crenças e [...] por isso não pode ser um pensamento originário" (Marcondes, 20I9, p. 9). Uma proposiçáo filosófica não pode, portanto, se sustentar na preexistência de um estado de mundo exterior a si mesma: tanto a suposição como a descrição de tal estado serấo partes inerentes de si mesma. Este parece ser, ainda, o sentido da ideia goodmaniana de que qualquer proposição é, antes de tudo, uma propriedade do quadro de referência que a contém ${ }^{9}$. Tal é sua condiçáo própria de inteligibilidade.

${ }^{9}$ Cf. Nelson Goodman, "Palavras, obras, mundos", 1995, p. 37-6I. 
6.

O sujeito do experimento "conflito das filosofias" é também sujeito de um vazio. É que a condição originária da prática filosófica - como calçada na intuição da discrepância - apresenta-se como a de um vazio originário; ou, se quisermos, como desdobramento de um núcleo de negatividade - promovido, por certo, por um "excesso" de positividade —, que acaba por deslocar a atenção para um novo avatar: não mais o investimento em um sistema de resolução do conflito das filosofias e de refutação dos sistemas rivais, mas a observação assustada da pluralidade dos mesmos. Há, pois, espanto ${ }^{10}$ e sensação de desenraizamento: por deraciné, o observador não sabe mais nada. Com efeito, se a história da filosofia, como assevera Porchat, é a história dos sistemas dogmáticos, a representação do seu conjunto como negaçáo peremptória da ideia de verdade que cada um dos sistemas garante poder "entregar" só pode ter como sujeito e suporte um observador que não sabe mais nada.

Ludwig Wittgenstein, no parágrafo I23 de suas Investigaçôes Filosóficas, dirá, um tanto socraticamente, que o vazio da posição — não saber mais nada — constitui a forma de um problema filosófico: "Um problema filosófico tem a forma: 'não sei mais nada" (Wittgenstein, I979, \$I23, p. 56). Trata-se, pois, de uma insipiência inscrita no modo da filosofia, posto que define a forma de um problema filosófico. Desta posição negativa resulta uma prática da filosofia que necessariamente se distingue da efetuada pelos filósofos dogmáticos, adeptos da inversão da proposição I23 de Wittgenstein. Creio que, sem maiores resistências, subscreveriam uma imaginária contra-proposiçâa I/I23: "Um problema filosófico tem a forma 'eu sei algo"'.

A intuição originária da cena primitiva do "conflito das filosofias" traz consigo a imagem oposta e terminal do fim da filosofia ou, ao menos, da inutilidade do caráter rebarbativo de seus jogos de refutaçáo recíproca e de autoconfirmaçáo. A filosofia perde, pois, o seu sentido mais arcaico de dizer o mundo. É exatamente isto que faz com que "eu náo saiba nada". Nos termos de Philippe Lacoue-Labarthe apresentase aqui um "limite intransponível", sob a forma de uma aporia: "não podemos mais — e só podemos - fazer filosofia, não dispondo de qualquer outra linguagem e não tendo a menor noção do que possa quer dizer 'pensar' fora do 'filosofar'" (Lacoue-Labarthe, 1987, p. I8).

Tratar-se-ia de um quadro de "modéstia" e de "suspensão da vontade": "não estão em nossas mãos nem a recusa nem a renúncia [...] não querer mais a filosofia, e não querer nada além dela" (Ibid., p. I8). O argumento de Lacoue-Labarthe pode ser coagulado da bela passagem a seguir:

\footnotetext{
10 "A descoberta da polêmica eterna entre os filósofos enche-os [os observadores porchatianos] de perplexidade e espanto, mas de um espanto que, por vezes, temam não venha a ser fecundo para a sabedoria”, Ibid., p. I8.
} 
A desistência, neste sentido, è vontade sem vontade, vontade não querendo mais e não se querendo mais, abandonando-se e deixando desarmar. Um imperativo muito obscuro, além ou aquém da simples recusa do que é dominante, ordena que deixemos desmoronar a filosofia dentro de nós e que nos tornemos receptivos a essa atenuação e a esse esgotamento da filosofia, hoje. É preciso não estar mais no desejo da filosofia (Ibid., p. 19).

Com efeito, a passagem constitui um enunciado alternativo - mas não substantivamente discrepante - à descrição do philósophos de Porchat, que não se quer mais filósofo, com a vantagem, creio eu, de o reinscrever no domínio da própria filosofia, atenuando seu estatuto déraciné. Sua marca distintiva residiria no reconhecimento da presença de uma vontade atenuada e em suspensão, como condição para permanecer na filosofia. A suspensão da vontade não é outra coisa senão a vontade de não dogmatizar, uma vontade condenada, em um primeiro passo, à negatividade. Para permanecer na filosofia, é necessário transformar a incredulidade em um problema filosófico. $\mathrm{Ou}$, de modo mais forte: trata-se de dizer que não há problema filosófico que não seja o da incredulidade: negar a qualquer proposiçâo valor de verdade.

Não por apego à miragem de uma decidibilidade fugidia e impossível, cuja falta far-me-ia filósofo, na verdade o filósofo desta lacuna. E sim pela negação de qualquer paradigma de decidibilidade filosófica. Em outros termos, e de modo mais radical: trata-se da negação do valor filosófico da própria ideia - e do ideal — de decidibilidade, sem transformar a sua falta em um fantasma filosófico - e retê-lo, desta maneira, como problema filosófico — , para o qual devemos retornar para confirmar nosso antidogmatismo. Não basta dizer dos jogos da equipolência que são filosoficamente "indecidíveis"; é necessário que se diga que a decidibilidade filosófica não é mais o caso.

É forte e incontornável, em Porchat, o enunciado da experiência do caráter "indecidível" do discurso filosófico. A ênfase na ideia de indecidibilidade, cujo suporte psicológico-epistêmico bem pode ter a forma de uma expectativa falhada, ou um desencaixe, acaba por o fixar como suporte lógico relevante o tema da decidibilidade. Com efeito, os sistemas dogmáticos sequer póem o tema da decidibilidade como problema, já que contém de modo autóctone e autárquico os termos suficientes para sua autovalidação. Entre a ostensão da verdade "objetiva” e a "certeza”, como intuiçáo inerente ao sujeito, não há hiato. O primeiro movimento contém o segundo, de modo necessário. O segundo movimento convém ao primeiro, de modo igualmente necessário.

Transformar a certeza auto suposta e inerente a cada sistema como modelo analítico de uma expectativa de decidibilidade, mesmo no contexto de uma refutação de sua possibilidade, significa mantê-la de algum modo no horizonte filosófico. 
Há, pois, sinais de uma nostalgia da decidibilidade, quando ao partir da constatação do conflito das filosofias afirmo a indecidibilidade, como seu corolário.

7.

Parece-me só haver abrigo possível para a ideia — e a expectativa — de decidibilidade, no âmbito da vida comum ou, para dizê-lo de outro modo, no das formas de vida dos humanos. Aqui "embaixo", artefatos e elementos de mediação resultam de processos dotados de fatores de decidibilidade, ainda que não necessariamente da intencionalidade. Tal decidibilidade vale tanto para os processos automáticos e intertemporais - tais como os inscritos na célebre metáfora hidrográfica de Montaigne, na Apologia de Raymond Sebond ${ }^{11}$ — quanto para os que resultam da intervenção intencional da vontade - como, por exemplo, o Edito de Nantes, de I598, que introduziu em França, no reinado de Henrique IV, o princípio da concórdia religiosa. Na verdade, quando considero o tema da decidibilidade prática, é o cenário aberto pelo Décimo Tropo de Enesidemo que tenho em vista.

O décimo da série de Tropos, apresentada por Sexto Empírico e por ele atribuída a Enesidemo de Cnossos, descreve o cenário da discrepância existente entre as formas de vida dos humanos ${ }^{12}$. Na letra de Sexto Empírico, trata-se do Tropo que lida com a dimensão da "Ética", ou dos fatores de organização das sociedades humanas. Ao fazê-lo, tal âmbito é representado como um conjunto de fatores, cujas variaçóes substantivas configuram formas de vida específicas, em um cenário agregado de dilatada variedade e discrepância. Segundo Sexto Empírico, tais fatores seriam os seguintes: regras de conduta, hábitos, leis, crenças lendárias e concepções dogmáticas (Sexto Empírico, 1986, p. 85). Cada sociedade particular preenche de modo próprio, e a seu tempo, aqueles fatores, de um modo tal que uma regra de conduta - a "escolha de um modo de vida" — adotada, por exemplo, por Diógenes não possa ser refutada demonstrativamente por outra praticada pelos Laconianos ${ }^{13}$. Tal variedade, somada à ausência de critério incontroverso de validação/invalidação, apresenta-se nos demais aspectos, o que faz do Décimo Tropo o primeiro abrigo filosófico do princípio da variedade cultural. Aqui também, é o cético que configura a

\footnotetext{
11 "As leis extraem da aplicação e do uso sua autoridade; é perigoso levá-las de volta a seu nascimento; elas se avolumam e enobrecem ao rolar, como nossos rios: acompanhai-os remontando até sua fonte e esta não passa de um pequeno olho d'água mal reconhecível, que assim se dignifica e se fortalece ao envelhecer. Vede as antigas consideraçóes que deram impulso a essa famosa torrente, plena de dignidade, de temor e de respeito: achá-las-eis táo leves e tão delicadas que estas pessoas aqui, que tudo pesam e remetem à razáo e que não aceitam coisa alguma por autoridade e em confiança, não é de espantar que amiúde seus julgamentos sejam tấo distantes dos julgamentos públicos". Cf. Michel de Montaigne, 2002, p. 376.

${ }^{12}$ Cf. Sexto Empírico, 1986, p. 85-93.

${ }^{13}$ Cf. Ibid., p. 85-87.
} 
variedade como cenário que não exige decisão a respeito de qual a forma de vida verdadeira. Os olhos de Heródoto, ativos e velados pelo dogma, tomaráo tal discrepância como sinal de variação em uma escala de perfeições. Para ele, segundo registrou Arnaldo Momigliano, os egípcios, em tudo o que fazem, teriam violado cláusulas básicas da humanidade ${ }^{14}$.

$\mathrm{Na}$ verdade, o que imagino é a possibilidade de reconsiderar os Dez Tropos de Enesidemo, tomando como ponto de partida o que supomos ser o seu elemento final ou, se quisermos, a sua aplicação prática sobre o domínio da experiência histórica: o Décimo Tropo sobre os Costumes e as Persuasóes. A leitura serial habitual induz-nos à suposição tácita de que o conjunto dos Dez Tropos representa uma série cumulativa, cujo resultado seria apresentação do cenário fático da diversidade cultural, em um vislumbre proporcionado pela aplicaçáo prática de uma téchne de suspensão do juízo. ${ }^{15}$

Por que não supor, como hipótese plausível, a possibilidade de que a sequência de apresentaçáo dos Tropos, tal como posta por Sexto Empírico, náo corresponda necessariamente a seu processo de concepção? Nesse caso hipotético, a intuição primária do observador cético poderia não ter sido a diferença entre os animais, mas, para dizê-lo em linguagem anacrônica, o "fato da diversidade cultural". A ordem possível dos fatores pode alterar a fisionomia e a matéria do resultado: no trajeto aqui imaginado, a intuiçấo do antropólogo teria preparado a do filósofo, a partir do momento em que o primeiro percebe que os fatores geradores de diversidade cultural são coextensivos ao domínio completo das circunstâncias e das representaçóes humanas. Ou seja, o Décimo Tropo pode, a meu juízo, ser pensado como passo na direçáo da intuição da diaphonía, posta por Agripa. Desta forma, ela não seria outra coisa senão a universalização das condiçóes nas quais a discrepância cultural entre os humanos se manifesta.

Por certo, o argumento é tecnicamente "improvável”. Por outro lado, penso não haver na apresentação das circunstâncias que conduzem à epoché, algo que interdite a conjectura que aqui apresento. $\mathrm{O}$ fato é que desconhecemos os termos originais nos quais os argumentos para a suspensão do juízo foram postos por Enesidemo de

\footnotetext{
14 Retirei a referência a Heródoto do extraordinário livro de Arnaldo Momigliano, I99I, p. II. A íntegra da passagem, contida no Livro II, sessão XXXV e, tal como reproduzida por Momigliano, é eloquente: "na maioria de seus hábitos e costumes os egípcios invertem exatamente os procedimentos usuais da humanidade".

15 Impressão reforçada pelo importante livro de Julia Annas e Jonathan Barnes, 1985. O livro redescreve os Dez Tropos de Enesidemo por meio de um recurso de formalização não-natural que acaba por fazer da epoché uma aplicação de uma téchne invariante de supensão, diante de todos os casos nos quais se apresentam discrepâncias. Tais discrepâncias são, portanto, apresentadas como aspectos naturais de um quadro ontológico objetivo e pré-filosófico. Se o dogmático é capaz de ver a natureza real das coisas, o cético é capaz de ver o fenômeno e de o depurar de todas as suplementaçóes delirantes. Mas, de onde vem esta ideia de um fenômeno depurado de acréscimos dogmáticos?
} 
Cnossos, em algum momento do século $\mathrm{I}$, anterior à Era Comum ${ }^{16}$. O que temos é a dedicada glosa de Sexto Empírico, efetuada três séculos mais tarde (II EC), que resultou na apresentaçáo de uma sequência que sugere um trajeto cumulativo, uma espécie de ordem das razóes para a suspensão do juízo.

Em outra ocasião, considerei o Décimo Tropo, para além de aplicação possível do mecanismo da epoché, como uma descrição analítica da forma básica da sociabilidade humana ${ }^{17}$. Esta resultaria da combinação dos cinco fatores indicados: regras de conduta, hábitos, leis, lendas (mitikàs pisteis) e concepçóes dogmáticas (dogmatikàs úpolépseis). É tal concepção a respeito da forma da sociedade que dá sentido à intuição de variedade que interdita a presença de critérios interculturais de "excomunhão e exclusão", para voltarmos à letra precisa de Porchat.

Julgo não ser de interesse menor notar que os fatores definidores da experiência humana resultam de decantações de dimensões dotadas de fundamento dogmático, cuja passagem ao ato - i. e., configuração de princípios normativos e práticos da interação social - define um campo específico de "prova". Em outros termos, o preenchimento substantivo das formas de vida abriga a decantação prática de enunciados de cariz dogmático, cujo conteúdo afeta significativamente o efeito produzido. O reconhecimento da presença de "crenças lendárias" e de "concepções dogmáticas" não conduziu, ao menos, o autor da glosa a sugerir a implacável aplicação do método da epoché. Na verdade, não era o caso: o que importava era mostrar o quanto da discrepância entre as formas de vida dos humanos resulta, entre outros fatores, dos efeitos práticos de enunciados dogmáticos, igualmente discrepantes. Temos aqui, portanto, aberta a via de uma reflexão a respeito de modos de decantaçáo de perspectivas e enunciados dogmáticos sobre a fábrica da vida comum. Não se trata, devo dizer, de destacar seus aspectos meramente adjetivos - como se fossem peças de uma "narrativa" de "homens doidos" que "dizem que as flores sentem", mas de atestar sua potência de afetação da natureza mesma dos fenômenos sociais.

Tais enunciados — tais como dizer, à moda do século XVII: "há direitos naturais" - estão epistemologicamente inscritos no campo dogmático, posto que exigem assentimento a proposiçôes não evidentes. Contudo, na descrição cética da forma de vida dos humanos, contida no Décimo Tropo, a cicatriz dogmática náo aparece como objeto de inquirição cética. Ali o que se mostra é a sua presença natural e ordinária na forma das sociedades e o que importa é considerar seus efeitos

\footnotetext{
16 O próprio Sexto Empírico abre a porta para alguma incerteza quanto à composição dos tropos: “...talvez esses argumentos náo sejam tão fortes assim, talvez existam mais tropos”. Ver Sexto Empírico, apud Danilo Marcondes, 2019, p. 54.

17 Cf. Renato Lessa, 1997.
} 
na composição das formas de vida. Há, pois, uma dimensão fabulosa e alucinatória na configuração dos arranjos humanos "realmente existentes", dotada de um atributo de produtividade ontológica.

O que o cético faz com isso, na economia interna de seus circuitos epistêmicos, não me interessa tanto: o que importa é ver que o problema está posto; o dogma lá está, no meio de nós, como elemento configurador de experiências com mundo, como elemento ativo que permite dizer algo para além daquilo que simplesmente parece estar diante de nós.

\section{8.}

Parto, portanto, da inclinação de considerar as formas de vida como espaços de decidibilidade, e não como dimensôes exógenas ao domínio da imaginação filosófica. Neste sentido, cabe a pergunta: a passagem ao ato, ao campo da experiência, de um enunciado dogmático produz efeitos que devem ser julgados como exteriores a seu núcleo interno originário e intocado? Não seria tal passagem um indicador existencial — distinto de um indicador filosófico "puro" - de decidibilidade? Em que medida um indicador existencial de decidibilidade é também um indicador filosófico?

Uma das escoras da Fórmula Porchat está contida na proposição de Martial Guéroult de que a filosofia é movida por uma "necessidade de antagonismo", e isto lhe confere um "aspecto histórico" (Guéroult, apud Porchat, 1986, p. I3). Porchat recepciona bem o ponto, ao afirmar que "a Filosofia se alimenta continuamente de si mesma e de sua própria história" (Ibid.). Mas, o quê, exatamente, confere "aspecto histórico" à prática filosófica? Uma das respostas possíveis está contida em uma interpretação restrita da proposição de Porchat, a respeito da, digamos, auto alimentação da filosofia. Uma implicaçáo importante da fórmula Guéroult-Porchat é a de afastar o espectro do contextualismo, um modo contra filosófico de fazer da história da filosofia um domínio cuja inteligibilidade resultaria de condiçóes ambientais externas e não-filosóficas.

Mas estes aspectos - história interna dos sistemas e história de seus conflitos, qua sistemas - englobam toda a dimensão possível da historicidade contida nos sistemas filosóficos? A resposta, por certo, depende do posicionamento adotado diante de uma questão maior, que diz respeito à relação entre filosofia e formas de vida. Tal relação, caso tomada como relevante, perece exigir a incorporação de uma ideia de "sistema filosófico" que, para além dos elementos internos, incorpora a presença de premissas e enunciados filosóficos na configuraçáo da experiência comum da vida. Uma outra resposta possível, portanto, consiste em considerar como problema filosófico os aspecto das decantaçóes e das passagens ao ato de concepçóes de mundo, urdidas no âmbito da filosofia — e não apenas no da filosofia política - 
como partes da grande manufatura das formas de vida. Náo se trata de resolver os dilemas do campo filosófico a partir de uma perspectiva advinda da experiência comum, mas de fazer o caminho exatamente oposto: o quanto da "visão comum do mundo" é afetado pela decantação de enunciados nada inocentes.

Os sistemas filosóficos "acontecem" para dentro de si mesmos ou seu âmbito "existencial" envolve necessariamente os efeitos de polinização que exercem sobre a experiência dos humanos? Em termos concretos, refiro-me a disseminação de maneiras de pensar e imagens conceituais que ganham materialidade no plano da vida ordinária. Penso em noçóes filosóficas, típicas do século XVII, tais como "estado de natureza" ou "lei natural" e observo o modo pelo qual foram empregadas na observação e na nomeação da experiência. Uma rápida leitura no preâmbulo da declaração de independência norte americana, aqui mencionada em nota anterior, ${ }^{18}$ basta para mostrar a força operativa da ideia de direitos humanos universais e a utilização do operador da evidência como marcador de verdade de enunciados políticos. O que dizer, ainda, da ideia de "autonomia"? Da ideia de "emancipaçáo"? Das teorias a respeito do tempo, do sentido da história e sobre a representação no campo da arte?

9.

Para dizê-lo à moda antiga, a "contradição principal" no campo do conflito das filosofias pode ser assim posta: trata-se da oposição entre dogmáticos — para os quais o tema da decidibilidade filosófica importa acima de tudo ${ }^{19}$ - e os náo-dogmáticos - para os quais a questão não faz sentido. Neste último caso, não há lugar para juízos de decidibilidade e qualquer abrigo para o seu fantasma, a indecidibilidade. A expectativa de decidibilidade filosófica, com efeito, só pode ser preenchida pelo modo da decidibilidade dogmática. Só haverá cura, portanto, para o vazio da indecidibilidade por meio da inoculação de veneno dogmático.

Há implicaçóes, creio, evidentes daquela distinção para a agenda dos filósofos que retiraram de seu horizonte o tema da decidibilidade filosófica. Penso que um modo possível de representação dessas implicaçôes pode ser o vislumbre de duas alternativas que se abrem ao filósofo que realizou a passagem para o espaço configurado pelo fim da decidibilidade e de seu fantasma: (i) uma agenda de contemplaçáo estética dos enunciados e sistemas — que não póe em tela de juízo seus efeitos externos e possíveis finalidades — ou (ii) uma agenda de corte construtivista -

\footnotetext{
18 Ver nota 5 .

19 Valho-me aqui da implicação necessária entre dogma e decisão filosófica, já que é da natureza do primeiro dizer a verdade de um modo tal que nenhuma proposiçáo alternativa possa aspirar estatuto assemelhado. É nesse sentido que o fantasma da decidibilidade inocula no filósofo que afirma a indecidibilidade o seu programa inegociável de dizer a verdade.
} 
à la mode de Goodman -, fundada na ideia de que sistemas simbólicos fabricam mundos, importando, pois, descrever os modos de fazer mundos com ênfase nos processos de passagem ao ato ${ }^{20}:$ momentos nos quais enunciados dogmáticos diversos constituem recipientes para a experiência dos humanos ${ }^{21}$.

Trocar - em sobrepasso terapêutico - o espaço vazio da indecidibilidade abstrata pelo âmbito impuro e confuso da decidibilidade prática: desde já, não há como fazêlo, a não ser por meio de um programa filosófico. Seu passo inicial é a intuição filosoficamente preparada - do conflito das filosofias. O passo seguinte consiste no trabalho de investigar o vasto campo das decantaçóes, um espaço escaleno no qual o sentido poiético da filosofia encontra endereço. Com efeito, o mundo parece mesmo ser tudo o que é o caso.

A Fórmula Porchat, mais do que o enunciado do problema filosófico originário de seu criador, indica os termos do programa originário para todo empreendimento filosófico não dogmático. Um programa, por certo, precedido por premissas filosóficas fortes. Sua condição de vigência é a presença de um operador de incredulidade ou, nos termos de Montaigne, um sujeito possuído por uma vontade de embêter les dogmatiques. Uma vontade cujos fundamentos não estáo, por certo, imunes ao temível Tropo da Regressão ao Infinito, da lavra do impiedoso Agripa. Suspeito, contudo, que mais do que denúncia de defeito lógico inerente aos dogmáticos, trata-se de sábia intuição antropológica. Afinal, nous sommes embarqués.

\section{Bibliografia}

Annas, J. e Barnes, J. (1985). The Modes of Scepticism: Ancient Texts and Modern Interpretation. Cambridge: Cambridge University Press.

Barnes, J. e Lawrence, G. (ed.) (1984). "Fragments", in: The Complete Works of Aristotle, v. II. Princeton: Princeton University Press.

Goodman, N. (1995). "Palavras, obras, mundos", in: Modos de Fazer Mundos, Porto: Edições ASA, p. 37-6I.

Lacoue-Labarthe, P. (1987). La fiction du politique, Paris: Christian Bourgois.

Lessa, R. (1997). Veneno Pirrônico: ensaios sobre o ceticismo, Rio de Janeiro: Francisco Alves.

${ }^{20}$ Cf. Nelson Goodman, 1995, p. 37-6I.

21 Tomo aqui a ideia de recipientes no sentido empregado por Primo Levi, em suas divagaçóes antropológicas, tal como postas no belo ensaio Una bottiglia di sole, 20I6, p. III3-III6. Nos termos da antropologia de Primo Levi, os humanos são "fabricadores de recipientes", vale dizer coletores de itens do mundo. A "recipientização" exige atribuição de sentidos e suplementação simbólica da experiência. 
Marcondes, D. (2019). Raízes da Dúvida: ceticismo e filosofia moderna. Rio de Janeiro: Zahar.

Michel de Montaigne. (2002). Ensaios. vol. II. São Paulo: Martins Fontes.

Momigliano, A. (I99I). Os Limites da Helenização: a interação cultural das civilizaçôes grega, romana, céltica, judaica e persa. Rio de Janeiro: Jorge Zahar.

Porchat Pereira, O. (1975). "Prefácio a uma filosofia", in: Discurso, 5(6), p. I05-I32.

Porchat Pereira, O. (1993). Vida comum e ceticismo. São Paulo: Ed. Brasiliense.

Porchat Pereira, O. e Prado Jr., B. (198I). A Filosofia e a Visão Comum do Mundo. São Paulo: Brasiliense.

Porchat Pereira, O. (2006). Rumo ao ceticismo. São Paulo: Ed. Unesp.

Primo Levi. (2016). Racconti e Saggi, in: Opere Complete de Primo Levi II, Torino: Einaudi.

Sexto Empírico. (1986). Outlines of Pyrrhonism, in Works, vol. I. Cambridge: Harvard University Press.

Wittgenstein, L. (1969). On Certainty. Oxford: Blackwell.

Wittgenstein, L. (1979). Investigaçôes filosóficas. Tradução de José Bruni, Coleção Os pensadores. São Paulo: Ed. Abril.

Wittgenstein, L. (1998). Notas Filosóficas, in Fernando Gil (ed.) Modos da Evidência. Lisboa: Imprensa Nacional/Casa da Moeda. 